\title{
Modular change impact analysis in factory systems
}

\section{Guideline for individual configuration}

\author{
Harald Bauer $^{1}$ (D) Paul Haase ${ }^{2} \cdot$ Fabian Sippl $^{1} \cdot$ Robert Ramakrishnan $^{2} \cdot$ Johannes Schilp $^{3} \cdot$ Gunther Reinhart $^{1}$
}

Received: 24 May 2020 / Accepted: 12 August 2020 / Published online: 7 September 2020

(c) The Author(s) 2020

\begin{abstract}
Shorter product innovation cycles, high variant products, and demand fluctuation, as well as equipment life cycles and technology life cycles force manufacturing companies to regularly change their manufacturing system. In order to address this challenge, an efficient and structured change management is required. As change causes and factory elements are connected via a complex network of relations and flows, an essential step in change management is the evaluation of considered adjustments with regard to their effects on the current production system. Depending on the context of the application, change impact analysis must process specific inputs and deliver different results. Current approaches, however, each focus only on selected aspects of the versatility of change effects. To address this challenge, this paper presents a modular approach for the individual design of change impact analysis.
\end{abstract}

Keywords Change impact analysis $\cdot$ Manufacturing system $\cdot$ Change management $\cdot$ Factory system

\section{Introduction}

Manufacturing systems are facing a high number of company external as well as company internal influence factors [59]. In case an altered requirement cannot be addressed with the available flexibility of the current system, changes or reconfigurations are required $[20,54]$. Due to the current

Harald Bauer

harald.bauer@iwb.tum.de

Paul Haase

Paul.Haase@bmw.de

Fabian Sippl

fabian.sippl@iwb.tum.de

Robert Ramakrishnan

robert.ramakrishnan@bmw.de

Johannes Schilp

johannes.schilp@igcv.fraunhofer.de

Gunther Reinhart

gunther.reinhart@iwb.tum.de

Technical University of Munich, Munich, Germany

BMW Group, Munich, Germany

3 Fraunhofer Research Institution for Casting, Composite and Processing Technology IGCV, Augsburg, Germany developments towards shorter innovation and product life cycles $[28,48]$ as well as customer individualization and higher product complexity $[44,50]$, the need for change occurs more and more often. In order to cope with the increasing frequency of changes, efficient change management processes are considered as crucial [26]. A prerequisite for successful change implementation within expected time and budget as well as for economical evaluation and decision-making is knowledge about all possible change impacts and necessary activities [40]. Therefore, approaches for change impact analysis (CIA) support this holistic assessment. However, the available methods only address specific aspects of the versatility of possible change impacts and are therefore only usable in a limited context. For a broad applicability in industry, this paper presents a modular approach, which can be individually designed according to the objective and starting situation of the analysis.

In order to specify the scope of work, Sect. 2 introduces general definitions and boundaries of this work. Subsequently, Sect. 3 presents the current state of the art and concludes with respective shortcomings and this contribution's objectives and benefits. Section 4 explains the methods and principles of the developed guideline for a modular and individual configuration of change impact analysis in factory systems. The guideline and its application within the 
automotive industry are described in Sects. 5 and 6. Sections 6.3 and 7 discuss and summarize the results and derive possibilities for future research activities.

\section{General definitions and scope of work}

A manufacturing system includes all procedures and facilities necessary for the transformation process of any type of inputs, tangible or intangible, to any type of higher valuable output [49]. It incorporates the levels of network, site, segment, system, cell, station, and processes [54]. This paper focuses on changes within a factory segment which compromises "the spatial arrangement, relations, and properties of technology, personnel, and infrastructure in a differentiable sub-section of a manufacturing plant" [41], "where the system boundary should be drawn technology- or productoriented" [40]. In this context, a factory or manufacturing change (MC) includes all "reconfiguration, alteration, addition, substitution, or removal of spatial arrangement, relations, and properties of technology, personnel, and infrastructure" [6]. Manufacturing change management (MCM) organizes and controls "the process of making alterations in manufacturing, including all measures to avoid or frontload and efficiently plan, select, implement and control manufacturing changes" [25].

A need for a factory change and thus its management can be the result of various company external as well as internal causes (cf. Fig. 1) [25]. Other authors also use similar or synonymous terms such as influencing factor [53], change driver [55] or trigger of change [12]. Most frequently, changes in factory systems are required due to product changes, quality issues, and efficiency improvement projects [26]. Many change causes follow a cyclic behavior and thus regularly trigger changes in a manufacturing system [59]. In particular in recurring cases, an efficient CIA is beneficial, as the type of change is known and similar behaviors can be expected in each case. Additionally, prepared models for the analysis can be used multiple times [6]. For entirely new situations and extensive change types-like sudden modifications of boundary and market conditions e.g. due to a pandemic-, an iterative and agile change management instead of a thorough change analysis - which might not be possible — can be suggested [8]. Furthermore, the reaction to change causes and the implementation of changes can be facilitated by the consideration of changeability [12] and resilience [17] within the design of manufacturing systems.

The CIA-focus of this paper-aims to identify a change's consequences under consideration of change propagation and consequent changes that are necessary to keep a compatible systems that fulfills all set requirements [1, $7,45]$. However, overall analysis goals as well as the starting point differ from approach to approach as section 3 will outline.

As the goal of this paper is an universal and modular approach for change impact analysis, manufacturing change impact analysis is considered as all efforts to create the required knowledge about a manufacturing change cause's

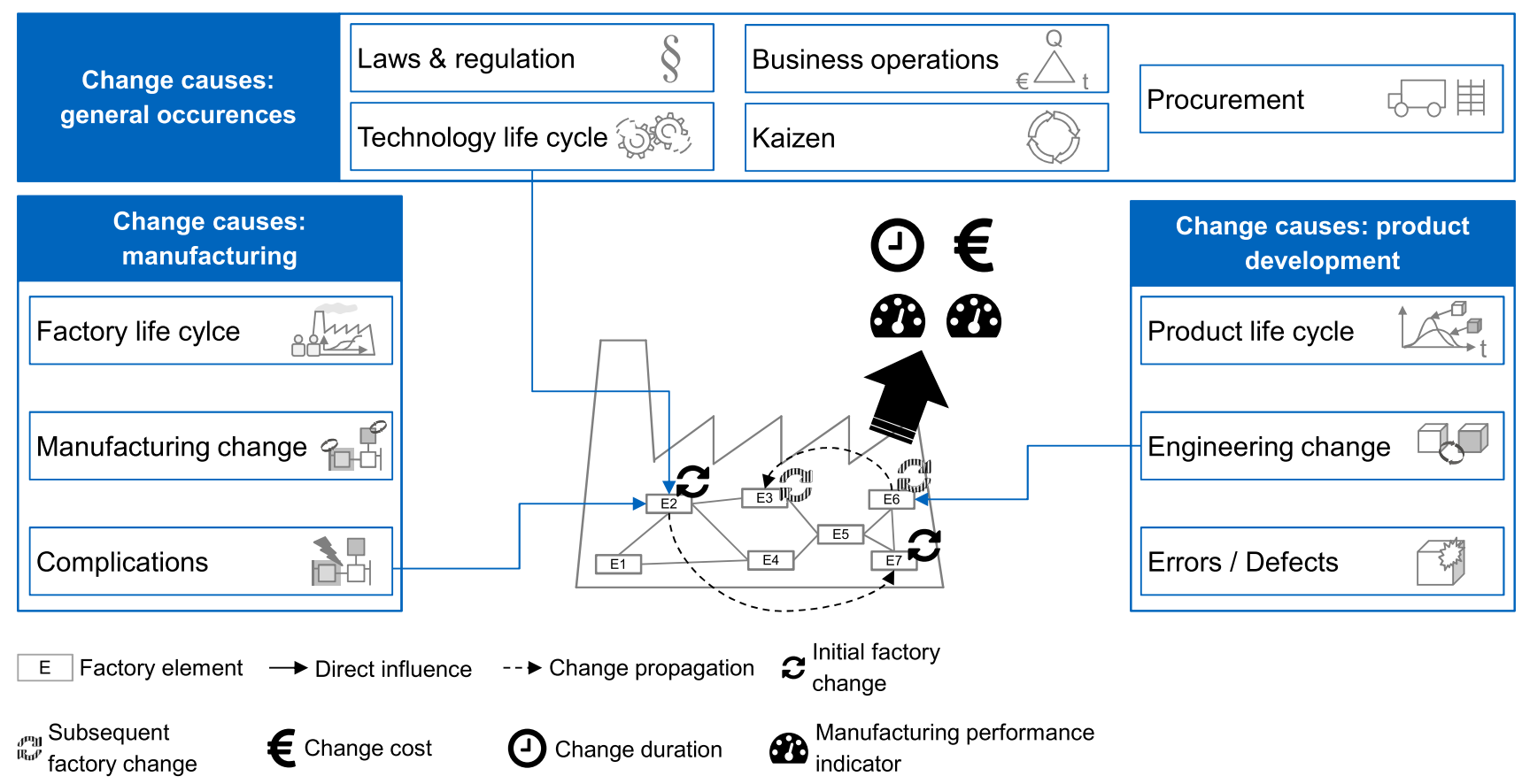

Fig. 1 Change causes, propagation, and impacts in factory systems (based on [5, 25, 39, 45]) 
propagation and impact in order to successfully implement the following planning activities within the specific change management process. This can include the determination of impacted factory elements, of the influence on manufacturing performance indicators, and of change costs and duration (cf. Fig. 1).

\section{Literature review}

The analysis and evaluation of change impacts is taken into account in all approaches for change management. While some authors provide a detailed description of the CIA, it is often only mentioned briefly.

\subsection{Change impact analysis within MCM processes}

The general concept of MCM was introduced by ProSTEP iViP e.V. [43]. In this generic multi-step process model the assessment of change impacts is already considered as one of the most critical steps for an efficient handling of MC. However, no statements about specific methods or considered target values of a CIA are made.

Based on this concept, Koch et al. [24] used an extensive literature research to develop a holistic MCM process. Within the first three stages of the process, the evaluation of change impacts takes place on different levels of detail [23]. The proactive change cause management comprises a short impact rating of change cause to enable a decision on the relevance of the MC. In order to identify all stakeholders of the potential MC, a risk and impact rating is applied. This analysis is further detailed within the conceptual problem solving to estimate investment costs and benefits based on all possible change propagation. While the process description provides detailed information about possible timings of CIA, no concrete methods for its application are provided [23].

Rößing [47] proposes a process for dealing with technical changes in production. Within this approach, a CIA is applied to identify impacted production objects and the impact's intensity [3]. The analysis is part of the phase "analysis of need for change". For this purpose, an interdependency matrix of production objects is established. The change impact between two elements is evaluated based on the elements' connectivity in work plans and their distance (i.e. direct or indirect interdependence). The analysis' results are the basis for resource allocation, budget planning, and scheduling for the subsequent change planning and implementation.

Further approaches do not focus specifically on MCs, in contrast they address specific problems of reconfigurations and adaptions of manufacturing systems. To plan the reconfigurations, key performance indicator (KPI) monitoring $[10,42]$, dependency matrices $[10,19,20,42]$, expert elicitation [20, 42], Monte Carlo Simulation [42], capability vs. requirement comparisons [20], if-else statements [19], and cost structures $[10,19,22]$ are used. Impact analyses are not clearly separated from the planning activities as they are integrated in an iterative planning process. Therefore, these approaches are not further detailed in this paper.

\subsection{Dedicated approaches for manufacturing change impact analysis}

Malak and Aurich [2, 32] introduced two different methods for the CIA of manufacturing changes in the course of their research. The approach presented in [32] examines the impacts on manufacturing layout, compatibility, and process chains. The objective is to derive necessary change activities from identified impacts in these areas. First, requirements of production objects and layout restrictions are investigated. Second, the interrelationships of production objects for material flow, handling, and manufacturing are verified. Concerning the process chain, the expected manufacturing time and costs are compared with the current values.

Within the second approach [2], change impact is predicted by the definition of general impact mechanisms. These always contain two elements of the analyzed system, the type of interconnection, the type of change, and the description as well as a qualitative indication (increase or decrease) of the impact on a certain indicator. When one part of a mechanism is changed, the documented change impact is indicated.

The approach of Plehn et al. [39, 40] aims to provide a decision support for manufacturing change management, particularly for the early conceptual phase that includes decisions about alternative changes, budget, and resources. Therefore, probability distributions for costs and duration of a change are estimated based on a factory graph-model, expert elicitation, and Monte Carlo Simulation.

Bauer et al. [6] present an approach to estimate the effects of manufacturing changes on any quantifiable production metric. Graph representations are used to model the factory elements and their interrelations as well as the network of production metrics. The verification of constraint satisfaction between factory elements is used to analyze change propagation and impacts.

Wulf [57] introduced an approach to evaluate and optimize the impacts of product and technology changes on factory systems. All relevant production and logistics segments are identified with the aid of dependency matrices. A GAP-Analysis is used to detect possible discrepancies between currently available and required skills. The different change alternatives are compared on basis of the necessary timely and monetary efforts. Expert estimations are used to quantify the number of required working days and the economic assessment is conducted with methods of investment 
analysis like the net present value method. The phenomenon of change propagation is not considered in this approach.

Kernschmidt and Vogel-Heuser [21] present an approach to analyze the effects of engineering changes on the complete lifecycle of production systems and compare change alternatives. Therefore, SysML4Mechatronics is applied to model the manufacturing system, its components, and their relations. Experts estimate further effects during the complete lifecycle with literature based checklists. Neither timely nor monetary efforts for changes are quantified and the possibility of change propagation is not directly addressed.

Nofen [37] presents a control loop based approach to detect and implement changes in modular factories. The need for changes is detected by the monitoring of specific change indicators. Starting from change triggers, analytically and empirically determined cause-effect-chains are used to identify directly affected factory elements. Expert knowledge is then used to determine indirect change effects and necessary timely efforts for change implementation.

\subsection{Shortcomings and problem statement}

Reviewing the relevant literature on CIA in manufacturing systems reveals that methods do not support company specific processes, goals, and general conditions. Each approach provides a procedure for a specific purpose and application case with different prerequisites. Authors define the required steps of the procedure and do not give any possibility for an individual customization neither according to the company's situation e.g. concerning expert knowledge, data availability, etc. nor the type or size of change.

This leads to a difficulty in selecting and applying available approaches as time-consuming adaptions might be necessary in order to prevent unnecessary modeling efforts and analysis steps as well as to integrate the analysis perfectly into existing processes. Current approaches do not allow users to configure the analysis' results according to their required knowledge for decision-making.

\subsection{Objective and benefits}

In general, a structured change impact analysis can lower the risk of undetected change impacts and improve the knowledge base for change planning and implementation [39].

In addition to existing approaches, this contribution aims to (1) enable companies to quickly design their individual but methodological and tool supported CIA, (2) improve the effort-value ratio in CIAs, and (3) improve the integration of CIA into existing processes.

Therefore, this approach guides the user step by step through the choice of CIA modules, module automation and certainty, documentation, and modeling. Possibilities are based on literature review and case studies in order to cover all alternative CIA applications. Analysis and modeling methods for each case are provided according to a broad literature evaluation of available approaches. In order to increase the applicability of the presented guideline, modeling templates and analysis tools were created.

\section{Methods of the developed guideline}

The following paragraphs provide a basic overview of the methods used within the guidelines for an individual design of change impact analysis in manufacturing systems (cf. Sect. 5).

Cognitive or causal maps: In many cases, a quantitative mapping of events' or elements' relation is either not possible - e.g. due to the fuzziness of the relation—or not necessary-due to the required output detail. In such cases, cognitive maps [4] or cause-effect maps [16] are applied. Thereby, arrows indicate the direction of a causality between linked concept variables [18]. These cause and effect relations are for example the basis for an effective use of indicator systems such as the Balanced Score Card [51].

Indicator system: An indicator system shows relationships between different variables and helps to organize indicators related to various functions within a company $[14,16]$. Indicator systems can be created for analysis and control purposes. They can be subdivided into calculation and classification systems, whereby in particular calculation systems are used for analysis purposes [15]. In calculation systems, key indicators are linked mathematically and arranged hierarchically.

Domain mapping matrix: One way to describe a complex system, such as a factory system, is to represent it in matrices [9]. A design structure matrix (DSM) or domain mapping matrix (DMM) systematically lists elements and relations to represent the system structure [30]. Relations within a domain (DSM) or between different domains (DMM) are identified by entries in the matrix. Matrix entries that are not equal to zero result in a numerical DSM or DMM, where entered values reflect a relation's strength, e.g. from minus two to plus two.

Value stream map: Value stream maps (VSM), which originate from the Toyota Production System, present all value-adding activities of product creation, from delivery of raw materials to delivery of finished products to customers. They contain production processes, business processes, material flows, information flows, customer, and supplier [13]. In the course of Industrie 4.0, the VSM 4.0 was developed by Meudth et al. [34]. In addition to classical value stream analysis, data acquisition, storage media, key figures, and information usage are displayed graphically in order to identify waste in information systems. 
Constraint network: A constraint network represents selected constraints that are related through shared variables [58]. It consists of a set of nodes representing the design variables and a set of arcs. Each arc connects two nodes and indicates the constraints between those two variables [38]. A constraint network allows the definite verification of change effects based on mathematical links.

Expert workshop: Expert workshops are planned and prepared working rounds which address a topic under guidance of a moderator and in a closed atmosphere [29]. An expert workshop consists of three parts: initial, working, and final phase.

Expert elicitation and uncertainty: To forecast change effects, it is usually necessary to involve experts at several points [39]. However, expert statements are always subject to a certain uncertainty, which must be addressed within the expert elicitation, for example, by asking for probability distributions instead of single values [35]. Different models and survey techniques are possible for this purpose. One of the most common approach is the three-point estimation from the Program Evaluation and Review Technique (PERT) [11,33]. Beta distributions are calculated based on the specification of a best case, a worst case, and a most likely case.

\section{Guideline for an individual design of change impact analysis in manufacturing systems}

The guideline consists of two main elements (cf. Fig. 2): (a) the procedure for individual CIA design, which uses the (b) CIA modules.

CIA modules are interchangeable analysis steps, which include methods, models, templates, and software tools. Each module aims to address a separate possible CIA goal. During the literature review, four main analysis results were identified and thus, four CIA modules exist (cf. Fig. 2). Depending on the context of the individual CIA, said results are required in a different level of certainty and should be achieved with a different level of automation. Therefore, each module can be further specified with an according certainty for the estimated result.

The procedure for individual CIA design starts with determining the analysis' position within the change management process (Step 1). On the one hand, it is essential to determine which steps have already been completed and thus serve as input for the analysis. On the other hand, knowledge concerning downstream process steps is required in order to determine the analysis' objectives.

Based on the objectives, the required analysis' modules, certainties, and levels of automation are selected (Step 2). Any number and combination of modules can be chosen.

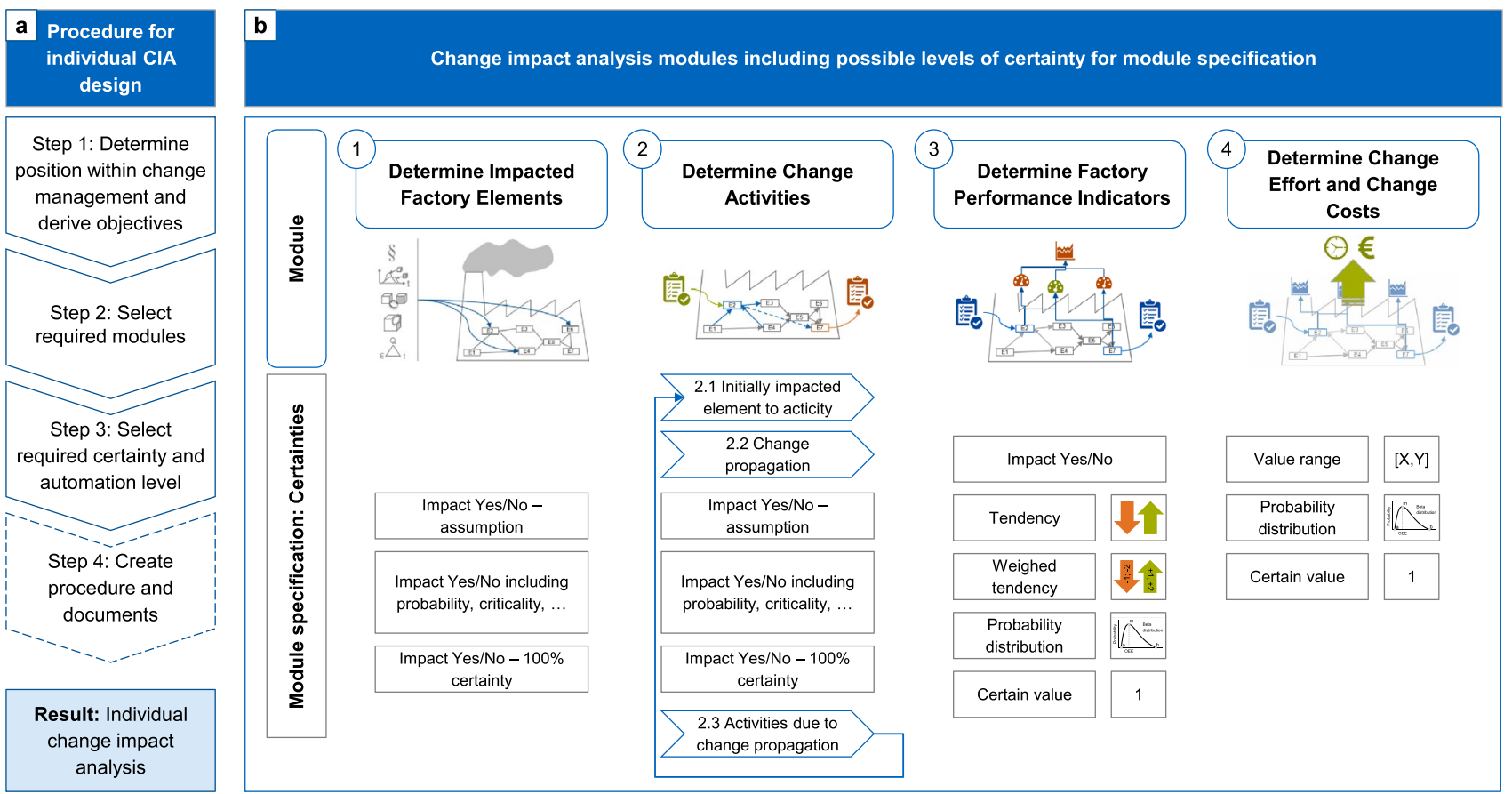

Fig. 2 Guideline for individual design of CIA—overview 
Within each module, different levels of certainty are chosen (Step 3). First, the level that is required for the final decision and as final result is selected. Subsequently, the levels of certainty, which shall be acquired with an automated tool support, are chosen. In general, the higher the level of automated certainty, the higher the initial modeling effort. Thus, it needs to be considered whether the additional modeling effort is lower than the regular manual analysis step e.g. an expert workshop-which would be required otherwise - and whether a model in the required detail is even possible. This depends for example on the size of the manufacturing system, the frequency of change, and the expert knowledge and availability. The different levels of certainty will be further addressed within the detailed module descriptions in Sects. 5.1 to 5.4 .

Based on the selection, the final procedure and required documents are created (Step 4) using the methods, models, templates, and software tools included in each CIA module.

\subsection{Module 1-determine impacted factory elements}

Module one analyses direct relationships between change causes and factory elements to ultimately identify a list of (potentially) affected factory elements.

Therefore, a DMM between changeable and relevant properties of change causes and factory elements-categorized in technology, area, organization, and documents according to Wiendahl et al. [54] -is modeled. Focus and level of detail depend on the application context and are chosen by the applying experts. The content within the DMM and thus also the analysis process differ depending on the required level of automatically determined certainty (cf. Fig. 3).

In case knowledge about potentially affected elements is sufficient without further specification, a basic DMM is completed with "" and "X".

Whenever a property of the change causes is selected or changed, the corresponding line of the DMM is searched for "X" and an impact is displayed for each match.

If more detailed information regarding the change impact is required, a numerical DMM is used. Entries in the matrices may vary depending on the information required. A criticality is expressed with a value range from 0 to 3 , while propagation probabilities are expressed in percent. The analysis result contains the additional information.

Following the evaluation, it is necessary to discuss the identified potential impacts with experts to decide whether these impacts are relevant or not.

In order to reduce efforts for expert evaluation, mathematical constraints can be entered into the DMM. Based on knowledge about quantified adjustment of change cause properties, constraint satisfactions are verified. Only if a constraint is no longer satisfied, a change effect is indicated. Further verification by experts is not necessary, but a higher modeling effort is required.

\subsection{Module 2-determine change activities}

Within module 2, specific factory changes are derived for impacted factory elements, if necessary, under consideration of change propagation.

In submodule 2.1, experts decide on required factory changes. An automated determination of a factory change based on the effects of a change cause or knowledge about
Fig. 3 Module 1: domain mapping matrix

\begin{tabular}{l}
\multicolumn{1}{c|}{$\begin{array}{c}\text { Technology / } \\
\text { Means }\end{array}$} \\
\cline { 2 - 6 }
\end{tabular}


impacted elements is not considered feasible with adequate effort.

In submodule 2.2, change propagation of each factory change is analyzed. The basis for this is a flow model of the factory system that represents all factory elements and their connections. Therefore, an extended VSM 4.0 is used. A VSM 4.0 represents process/stations, material flows, information flows, and IT systems. Based on Plehn et al. [41], building and room technology, media flows, personnel flows, and energy flows must also be modeled. Figure 4 shows an example of an extended VSM 4.0.

Based on this model, a connection analysis is possible. It indicates which connections originate from the changed factory element and thus provides information on change propagation. Experts must then analyze whether the connections lead to further change needs.

More detailed information can be provided by embedding a propagation criticality or probability in each flow connection (cf. Fig. 4). This can be useful to prioritize the evaluation of the connection analysis. However, it is still necessary for experts to check the relevance of each connection.

As in module 1, a clear estimation of change impacts is possible by modeling mathematical constraints, in this case between the properties of factory system elements (cf. Fig. 4). Constraints result either from manufacturing objectives and metrics, e.g. cycle time, line balancing, etc., or from the compatibility of all elements, e.g. the format of stored data or the position of parts in their containers. The more conditions are mapped during system modeling, the less expert knowledge is required to analyze the effects of changes.

In submodule 2.3, concrete consequential changes are derived by experts from identified change needs due to change propagation.

\subsection{Module 3-determine factory performance indicators}

Module 3 covers the change impact analysis on a factory's performance indicators. Five levels of certainty based on different models are possible (cf. Fig. 5).

If a tendency or a weighed tendency concerning the behavior of an indicator due to the factory changes is sufficient, a simple cognitive map is used. Experts need to indicate the change on the lowest indicator level in the required certainty and the impact on top indicators is estimated.

In case, a quantified estimation of changed indicator values is required, a calculation indicator system is

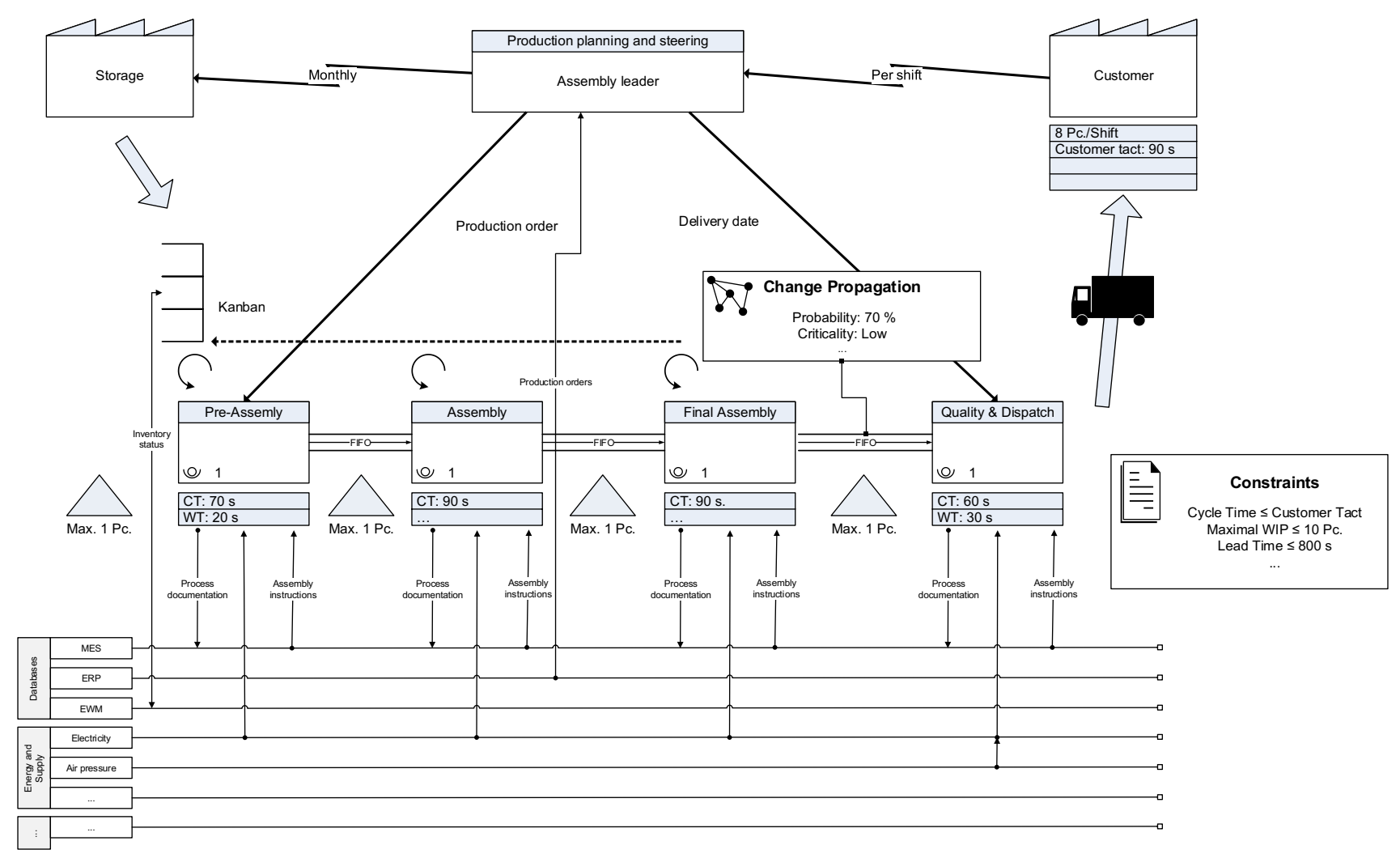

Fig. 4 Module 2: example—extended value stream map of the learning factory for lean manufacturing 
Fig. 5 Module 3: examplecognitive map and calculation indicator system (overall equipment efficienty OEE based on [36])

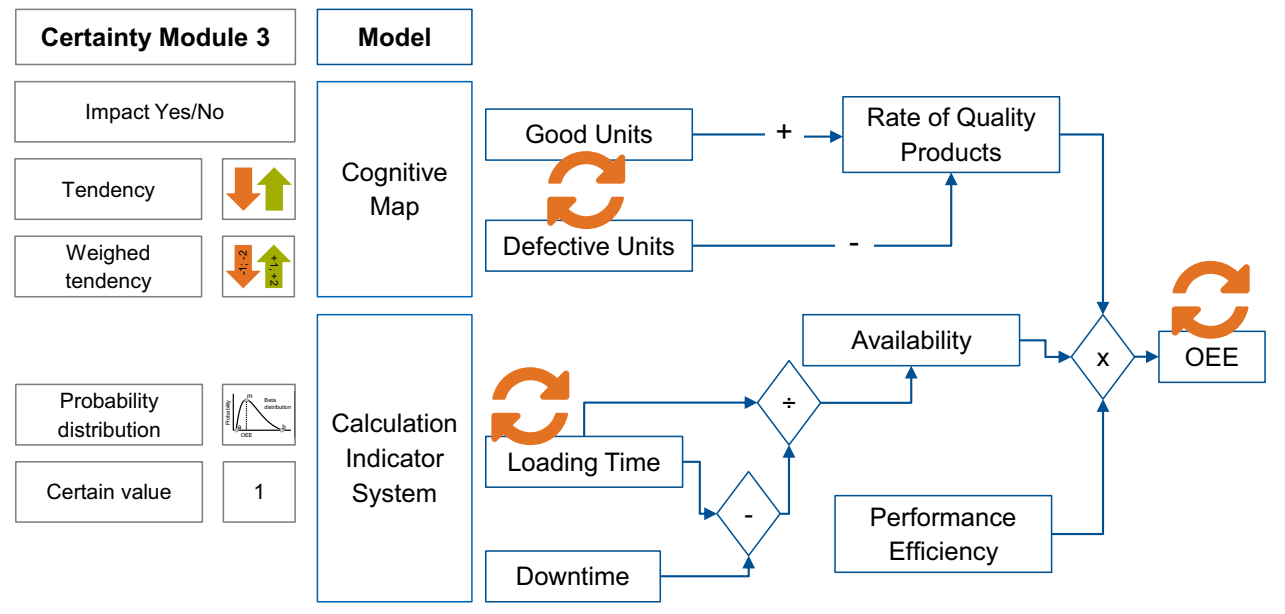

modeled. As before, experts need to specify indicator changes in the required certainty, thus, a certain value or a probability distribution based on a three point estimation. Subsequently, the changed top indicator is calculated.

\subsection{Module 4-determine change effort and change costs}

Module 4 is the estimation of change effort-work timeand changes costs-personnel and investment. Therefore, a cost structure for change cost evaluation was created, which can be found in [27]. It is structured according to the change management process presented by Rößing [47]. Based on literature review and expert interviews, 71 cost items were assigned to each substep. However, it is possible to add or further specify cost positions when required.

Each cost item can be evaluated either with a certain value, a value range, or a three-point-estimation, depending on the desired information detail and the acceptable modeling effort.

Within the final CIA procedure, it is possible to separate the cost structure in items that are similar for each change, and items that highly depend on specific change details. This way, only a part of the evaluation needs to be repeated in each CIA. Otherwise it is also possible to classify all changes and complete a reusable evaluation once for each change type.

\section{Application within the automotive industry}

\subsection{Detailed description of the industrial case}

The goal of an industrial application, by free selection of the available modules, their methods and degrees of detail, takes place under consideration of company-specific restrictions. These restrictions refer for example to already existing methods, which are used for the planning of change projects [46]. Starting point of the investigation are changes of additive manufactured components within the automotive industry at the BMW Group, in order to be able to optimally exploit the advantages of tool-neutral product changes of the additive manufacturing process within the supply chain $[52,56]$.

On one side, these cause interactions of a variety of product properties [31]. Changing the position of a feature on a product with the same force input has a direct effect on its size and shape, because of its changed force flow. In addition, this adaptation influences the product volume and thus the component weight [56]. On the other side, each property is directly affecting the manufacturing system. For example, adjusting the feature position affects the Selective Laser Melting (SLM) process parameters due to the new shape. Furthermore, the automated handling process is affected by the adaptation of the component and its potential interfering contours. Due to the new component weight, the adjusted batch size of a construction job has in turn an effect on the production control of individual delivery orders.

\subsection{Design of the individual change impact analysis}

The company already applies a change evaluation tool, in which every affected employee needs to enter an estimation of direct change propagation and change costs. However, within the additive manufacturing process, no support for a fast identification of said employees and the most important change impacts for them to verify and evaluate is available.

Thus, goal of the CIA is to provide quick information about influenced processes and process parameters including a prioritization as basis for expert selection and evaluation (Step 1). At this stage, parameter lists of the automated processes, inspection characteristics from quality specifications and implied knowledge of the experts represent the available 
data basis for the CIA. The experts of all influenced departments can then be specified by the organizational structure and its interfaces.

Therefore, module 1 (Step 2) was selected as most important part of the CIA. In this module, the product to process interaction is modeled. This knowledge was considered as particularly important in the context of additive manufacturing, as it also provides information on how the product can be changed within the high degrees of freedom of the technology to facilitate the manufacturing process. Change propagation (module 2) between processes was neglected by experts because of low interdependence within the process chain. Specific change activities are determined in a regular meeting by the impacted areas. With regard to the existing evaluation system for changes, the analysis of performance indicators (module 3 ) and the cost consideration (module 4) were not further considered.

As the final discussion of change impacts is part of an expert meeting, the certainty "Impact Yes/No including criticality" was chosen as necessary specification for final result and level of automation of module 1 (Step 3). This was also considered the best option for a first implementation with regard to later on increasing the certainty and evaluation detail by modeling mathematical constraints.

As shown in chapter 5.1, DMMs with value entries ranging from 0 to 3 were established based on expert interviews to link product features with the manufacturing system.
A DMM was completed for each area of potentially high impact. For this purpose, the influencing characteristics of additive manufacturing products were adapted or specified from literature based on the application case and then supplemented by process-specific knowledge of the experts (cf. Fig. 6, (Step 4)).

As a part of this application, the interactions of product properties have been analyzed and documented in an additional DSM to analyze change propagation within the components when discussing a product change.

With the help of this documentation, a repeatable analysis is possible using a software-based application. For this purpose, a CIA tool was developed in Matlab, which enables a transparent assessment of technical effects at an early stage. The software application (cf. Fig. 6), visualizes the component properties, which can be selected and changed, in the upper left area. To identify the impacts of a product change, e.g. the feature location, the component property is selected in the top left and the most important impacts on the process characteristics are listed as analysis results on the right side based on the DMMs (cf. Fig. 6). The direct dependencies are illustrated using a color coding for the three different criticalities $($ red $=3 /$ strong, yellow $=2 /$ medium, green $=1$ / weak). The lower left area visualizes the active and passive sums of product properties according to the DSM.

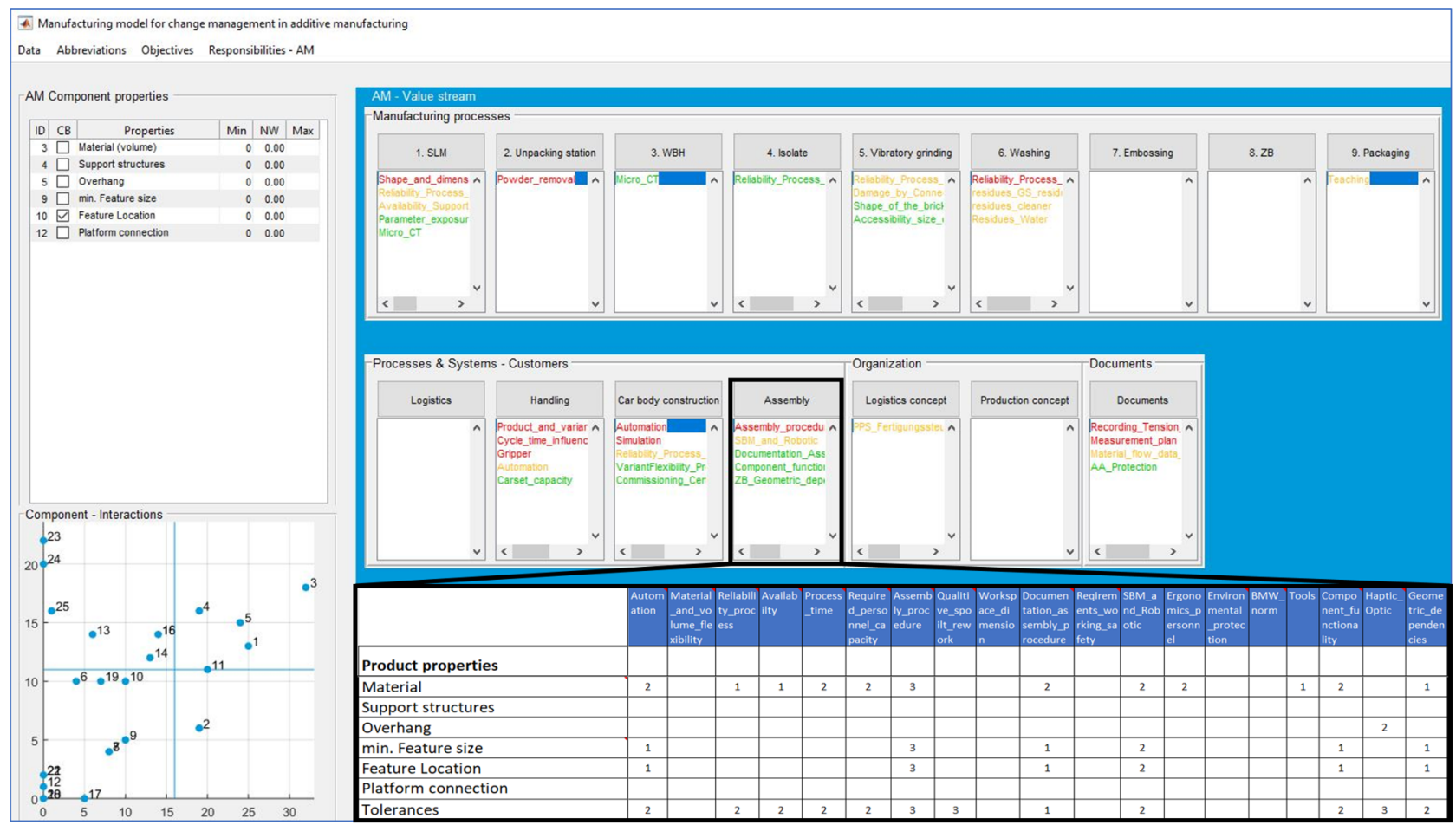

Fig. 6 CIA tool 


\subsection{Discussion and limitations}

On the one side, the application demonstrated the advantages of the modular approach. The guideline for an individual design of the CIA provided a fast possibility to identify the necessary models and analysis tools in order to create a suited procedure. It enabled a target-oriented analysis and evaluation of the overall system, without causing any unnecessary detail in the modeling efforts. It helped the experts to specify and structure the overall problem by themselves, which led to a high acceptance of the experts during the implementation.

The advantage of the resulting CIA is the possibility to evaluate changes in detail and to incorporate them into future development work. The possibility of a repeated application of the CIA leads to a reduced evaluation effort, supports technical assessment for all stakeholders, and creates transparency. Additionally, the collected knowledge is retained and the evaluations or analyses are not negatively influenced by employee changes within the company. Furthermore, the quality of the assessment is increased due to already documented knowledge. Integrating a holistic and standardized monetary assessment (cf. module 4) to complement the company-specific change evaluation process and tool for product caused change projects could further support the decision on concrete changes.

The effort per DMM for the implementation was about 5 min per product characteristic with a total number of 10-20 influencing characteristics. This number should neither be exceeded nor reduced due to the desired informative value of the evaluation. Thus a total evaluation effort per DMM of approx. 50-100 min was necessary. The reason for this are longer discussions about the classification of different influencing properties. Besides the mentioned qualitative advantages, the CIA could help to reduce the effort for the detailed evaluation within the existing system by approx. $10 \mathrm{~min}$ per change. The ratio between modeling effort and reduced evaluation effort shows, that the resulting CIA is designed for a repeated application on cyclic changes (see Sect. 2). In the application context, the experts need to analyze several changes per week. However, the high manual effort for data maintenance of characteristics and their impacts is still reducing the benefits of the created CIA. An automated data management and maintenance would guarantee the lasting usability of the collected data.

Current limitations of the presented approach of this paper are due the need for further industrial evaluations in future research activities. The major aspects that need to be examined are the approach's use in larger manufacturing systems and for different change causes. Concerning different change causes, the challenge is the selection of change cause properties, which describe e.g. a manufacturing technology in a general way to enable a repeated analysis. For larger manufacturing systems, a higher modeling effort is expected, however, the benefit due to the complexity of the system should also increase. As explained in Sect. 5, this challenge is addressed by the individual selection of module certainties and model detail, which has been proven valuable in the described application in the automotive industry.

\section{Conclusion and outlook}

The diversity of change causes, change management processes, and CIA contexts is the major challenge for the presented approach. Therefore, a modular structure of change impact analysis is presented, which enables companies to quickly design their individual procedure to address their specific requirements. Currently, the procedure was evaluated in the context of product changes as change cause. The advantage of the presented procedure is the practicable and industrial applicability, which is ensured by a free choice of four available modules and their methods as well as a degree of certainty.

Further research activities will focus on industrial applications in change scenarios due to additional causes as technology life cycles or laws and regulations as well as in larger manufacturing systems. Furthermore, in this context, the selection of change cause characteristics that are modeled in order to determine indirect impacts on the manufacturing system will be detailed. In addition, future research should also focus on the assessment of change effects in an early phase of organizational process planning of production systems and its operational strategy.

Acknowledgements The German Research Foundation funded this research and development project. We extend our sincere thanks to the DFG for its generous support of the work described in this paper, which results from the Collaborative Research Centre 768 "Managing cycles in innovation processes-Integrated development of product service systems based on technical products". We also thank the BMW Group for the comprehensive support for this work.

Funding Open Access funding provided by Projekt DEAL.

\section{Compliance with ethical standards}

Conflict of interest The authors declare that they have no conflict of interest.

Open Access This article is licensed under a Creative Commons Attribution 4.0 International License, which permits use, sharing, adaptation, distribution and reproduction in any medium or format, as long as you give appropriate credit to the original author(s) and the source, provide a link to the Creative Commons licence, and indicate if changes were made. The images or other third party material in this article are included in the article's Creative Commons licence, unless indicated otherwise in a credit line to the material. If material is not included in the article's Creative Commons licence and your intended use is not permitted by statutory regulation or exceeds the permitted use, you will 
need to obtain permission directly from the copyright holder. To view a copy of this licence, visit http://creativecommons.org/licenses/by/4.0/.

\section{References}

1. Arnold RS, Bohner SA (1993) Impact analysis-towards a framework for comparison. In: Card D (ed) Proceedings /conference on software maintenance 1993. IEEE Computer Soc. Press, Los Alamitos, pp 292-301. https://doi.org/10.1109/ICSM.1993.36693 3

2. Aurich JC, Malak RC (2010) Engineering change mechanisms in manufacturing. Wt Online 100(1/2):15-21

3. Aurich JC, Rößing M (2007) Engineering change impact analysis in production using vr. In: Cunha PF, Maropoulos PG (eds) Digital enterprise technology. Springer Science+Business Media LLC, Boston, pp 75-82. https://doi.org/10.1007/978-0-387-49864-5_8

4. Axelrod R (2015) The analysis of cognitive maps. In: Axelrod $\mathrm{R}$ (ed) Structure of decision, Princeton legacy library. Princeton University Press, Princeton, pp 55-73

5. Bauer H, Brandl F, Reinhart G (2018) Manufacturing change impact analysis: approach for an individual design. ZWF Zeitschrift für wirtschaftlichen Fabrikbetrieb 113(12):819-823. https://doi.org/10.3139/104.112018

6. Bauer H, Schoonmann A, Reinhart G (2017) Approach for modelbased change impact analysis in factory systems. In 2017 IEEE international systems engineering symposium (ISSE), pp. 1-7. https://doi.org/10.1109/SysEng.2017.8088301

7. Bohner SA (2002) Software change impacts - an evolving persepective. Proc IEEE Int Conf Softw Maint 1:263-272

8. Brandl FJ, Kagerer M, Reinhart G (2018) A hybrid innovation management framework for manufacturing-enablers for more agility in plants. Procedia CIRP 72:1154-1159. https://doi. org/10.1016/j.procir.2018.04.022

9. Browning TR (2001) Applying the design structure matrix to system decomposition and integration problems: a review and new directions. IEEE Trans Eng Manag 48(3):292-306. https://doi. org/10.1109/17.946528

10. Cisek R (2005) Planung und Bewertung von Rekonfigurationsprozessen in Produktionssystemen, Forschungsberichte IWB, vol. 191. Utz, München

11. Clark CE (1962) Letter to the editor-the pert model for the distribution of an activity time. Oper Res 10(3):405-406. https://doi. org/10.1287/opre.10.3.405

12. ElMaraghy HA (2009) Changeable and reconfigurable manufacturing systems. Springer London, London. https://doi. org/10.1007/978-1-84882-067-8

13. Erlach K (2013) Value stream design: the way towards a lean factory. Lecture notes in logistics. Springer, Berlin and Heidelberg

14. Franceschini F, Galetto M, Maisano D (2019) Designing performance measurement systems: theory and practice of key performance indicators. Management for professionals. Springer International Publishing, Cham. https://doi.org/10.1007/978-3030-01192-5

15. Gladen W (2001) Kennzahlen- und Berichtssysteme: Grundlagen zum performance measurement. Gabler Verlag, Wiesbaden. https ://doi.org/10.1007/978-3-322-86703-2

16. Gladen W (2014) Performance measurement: controlling mit Kennzahlen, 6., überarb. aufl. edn. Springer-Lehrbuch. Springer Gabler, Wiesbaden

17. Gu X, Jin X, Ni J, Koren Y (2015) Manufacturing system design for resilience. Procedia CIRP 36:135-140. https://doi. org/10.1016/j.procir.2015.02.075
18. Hall RI, Aitchison PW, Kocay WL (1994) Causal policy maps of managers: formal methods for elicitation and analysis. Syst Dyn Rev 10(4):337-360. https://doi.org/10.1002/sdr.4260100402

19. Hermann L, Rey J, Bergs T (2019) Methodology for an integrative manufacturing change management in technology planning for medical products. International conference on competitive manufacturing (COMA '19)

20. Karl F, Reinhart G (2015) Reconfigurations on manufacturing resources: identification of needs and planning. Prod Eng 9(3):393-404. https://doi.org/10.1007/s11740-015-0607-x

21. Kernschmidt K, Vogel-Heuser B (2013) An interdisciplinary sysml based modeling approach for analyzing change influences in production plants to support the engineering. In: 2013 IEEE international conference on automation science and engineering (CASE), pp. 1113-1118. IEEE. https://doi.org/10.1109/CoASE .2013 .6654030

22. Klocke F, Müller J, Mattfeld P, Kukulies J, Schmitt RH (2018) Integrative technology and inspection planning - a case study in medical industry. J Manuf Sci Eng 140(5):051002. https://doi. org/10.1115/1.4039114

23. Koch J (2017) Manufacturing change management-a processbased approach for the management of manufacturing changes. Dissertation, Technical University of Munich, Munich

24. Koch J, Gritsch A, Reinhart G (2016) Process design for the management of changes in manufacturing: toward a manufacturing change management process. CIRP J Manuf Sci Technol 14:1019. https://doi.org/10.1016/j.cirpj.2016.04.010

25. Koch J, Hofer A (2016) Manufacturing change management. WT Werkstattstechnik, pp. 520-526

26. Koch J, Michels N, Reinhart G (2016) Context model design for a process-oriented manufacturing change management. Procedia CIRP 41:33-38. https://doi.org/10.1016/j.procir.2015.12.111

27. Kröger S, Bauer H, Reinhart G (2019) Cost structure for change impact evaluation in manufacturing systems. ZWF Zeitschrift für wirtschaftlichen Fabrikbetrieb 114(9):530-534. https://doi. org/10.3139/104.112140

28. Kumar S, Krob WA (2005) Managing product life cycle in a supply chain. Springer, US. https://doi.org/10.1007/b101080

29. Lienhart A (2015) Seminare, trainings und workshops lebendig gestalten. Haufe TaschenGuide. Haufe-Lexware GmbH \& Co. KG, Freiburg

30. Lindemann U, Maurer M, Braun T (2009) Structural complexity management. Springer, Berlin, Heidelberg. https://doi. org/10.1007/978-3-540-87889-6

31. Lindemann U, Reichwald R (1998) Integriertes Änderungsmanagement. Springer, Berlin, Heidelberg. https://doi. org/10.1007/978-3-642-71957-8

32. Malak RC, Aurich JC (2013) Software tool for planning and analyzing engineering changes in manufacturing systems. Procedia CIRP 12:348-353. https://doi.org/10.1016/j.procir.2013.09.060

33. Malcolm DG, Roseboom JH, Clark CE, Fazar W (1959) Application of a technique for research and development program evaluation. Oper Res 7(5):646-669. https://doi.org/10.1287/opre.7.5.646

34. Meudt T, Rößler MP, Böllhoff J, Metternich J (2016) Value stream mapping 4.0. ZWF Zeitschrift für wirtschaftlichen Fabrikbetrieb 111(6):319-323. https://doi.org/10.3139/104.111533

35. Morris DE, Oakley JE, Crowe JA (2014) A web-based tool for eliciting probability distributions from experts. Environ Model Softw 52:1-4. https://doi.org/10.1016/j.envsoft.2013.10.010

36. Nakajima S (1990) Introduction to TPM-total productive maintenance, 5 edn. Productivity Pr, Cambridge, Mass. [u.a.]

37. Nofen D (2006) Regelkreisbasierte Wandlungsprozesse der modularen Fabrik: Zugl.: Hannover, Univ., Diss., 2006, Berichte aus dem IFA, vol. 2006, 1. PZH Produktionstechn. Zentrum, Garbsen 
38. Ou-Yang C, Chang CW (1999) Developing an integrated intelligent framework to support an engineering change process for an axial piston pump. Int J Adv Manuf Technol 15(5):345-355. https://doi.org/10.1007/s001700050077

39. Plehn C (2017) A method for analyzing the impact of changes and their propagation in manufacturing systems. Dissertation, Herbert Utz Verlag $\mathrm{GmbH}$

40. Plehn C, Stein F, de Neufville R, Reinhart G (2016) Assessing the impact of changes and their knock-on effects in manufacturing systems. Procedia CIRP 57:479-486. https://doi.org/10.1016/j. procir.2016.11.083

41. Plehn C, Stein F, Reinhart G (2015) Modeling factory systems using graphs - ontology-based design of a domain specific modeling approach. In: Weber C, Husung S, Cantamessa M, Cascini G, Marjanovic D, Graziosi S (eds) DS 80-4 Proceedings of the 20th International Conference on Engineering Design (ICED 15) Vol 4: Design for X, Design to X, Milan, Italy, 27-30 July 2015. Technische Universitaet Muenchen, Germany, pp 163-172. https://www.designsociety.org/publication/37777/ MODELING+FACTORY+SYSTEMS+USING+GRAPHS++ONTOLOGYBASED+DESIGN+OF+A+DOMAIN+SPECI FIC+MODELING+APPROACH

42. Pohl J (2014) Adaption von Produktionsstrukturen unter Berücksichtigung von Lebenszyklen: Zugl.: München, Techn. Univ., Diss., 2013, Forschungsberichte IWB, vol. 284. Utz, München

43. ProSTEP iViP e.V. (2014) Manufacturing change management (white paper): management von Änderungen in der produktion (management of changes in production), Darmstadt. https://www. prostep.org/mediathek/veroeffentlichungen/?no_cache $=1$

44. Rebentisch E, Schuh G, Riesener M, Breunig S, Pott A, Sinha K (2016) Assessment of changes in technical systems and their effects on cost and duration based on structural complexity. Procedia CIRP 55:35-40. https://doi.org/10.1016/j.procir.2016.07.033

45. Richter L, Lübkemann J, Nyhuis P (2014) Development of a model for the redesign of plant structures. Int J Soc Educ Econ Manag Eng 8:3295-3298

46. RIIS JO (1990) The use of production management concepts in the design of production management systems. Prod Plan Control 1(1):45-52. https://doi.org/10.1080/09537289008919293

47. Rößing M (2007) Technische Änderungen in der Produktion Vorgehensweise zur systematischen Initialisierung, Durchführung und Nachbereitung: Zugl.: Kaiserslautern, Techn. Univ., Diss., 2007, Produktionstechnische Berichte aus dem FBK, vol. 2007,2, als ms. gedr edn. Techn. Univ, Kaiserslautern

48. Schönmann A, Ulverich M, Intra C, Reinhart G (2016) Considering external and internal cycles of a manufacturer for planning and evaluating production technologies. Procedia CIRP 55:47-52. https://doi.org/10.1016/j.procir.2016.08.006
49. Schuh G (2014) Produktionsmanagement: Handbuch Produktion und Management 5, Handbuch Produktion und Management, vol. 5, 2. aufl. edn. Springer Vieweg, Berlin

50. Schuh G, Schroder S, Lau F, Wetterney T (2016) Next generation hardware development: requirements and configuration options for the organization of procurement activities in the context of agile new product development. In: 2016 Portland international conference on management of engineering and technology (PICMET), pp. 2583-2591. IEEE (04.09.2016 - 08.09.2016). https:// doi.org/10.1109/PICMET.2016.7806809

51. Wall F (2001) Ursache-wirkungsbeziehungen als ein zentraler bestandteil der balanced scorecard. Controlling 13(2):65-74. https ://doi.org/10.15358/0935-0381-2001-2-65

52. Weber MA, Lakomiec M (2017) Additive fertigung für die industrielle produktion. ZWF Zeitschrift für wirtschaftlichen Fabrikbetrieb 112(11):741-744. https://doi.org/10.3139/104.111809

53. Westkämper E, von Briel R (2001) Continuous improvement and participative factory planning by computer systems. CIRP Ann Manuf Technol 50(1):347-352. https://doi.org/10.1016/S0007 $-8506(07) 62137-4$

54. Wiendahl HP, ElMaraghy HA, Nyhuis P, Zäh MF, Wiendahl HH, Duffie N, Brieke M (2007) Changeable manufacturingclassification, design and operation. CIRP Ann Manuf Technol 56(2):783-809. https://doi.org/10.1016/j.cirp.2007.10.003

55. Wiendahl HP, Nofen D, Klußmann JH, Breitenbach F (2005) Planung modularer Fabriken. Carl Hanser Verlag GmbH \& Co. KG, München. https://doi.org/10.3139/9783446436022

56. WOHLERS TT (2018) Wohlers report: 3d printing and additive manufacturing state of the industry. WOHLERS Associates, Fort Collins

57. Wulf S (2011) Bewertung des Einflusses von Produkt- und Technologieveränderungen auf die Fabrik, Berichte aus dem IFA / Institut für Fabrikanlagen und Logistik, vol. 02/2011. PZH Produktionstechnisches Zentrum, Garbsen

58. Young RE, Greef A, O'Grady P (1992) An artificial intelligencebased constraint network system for concurrent engineering. Int J Prod Res 30(7):1715-1735. https://doi.org/10.1080/0020754920 8948116

59. Zaeh MF, Reinhart G, Karl F, Schindler S, Pohl J, Rimpau C (2010) Cyclic influences within the production resource planning process. Prod Eng 4(4):309-317. https://doi.org/10.1007/s1174 0-010-0254-1

Publisher's Note Springer Nature remains neutral with regard to jurisdictional claims in published maps and institutional affiliations. 